\title{
Successful Strategies for Using Knowledge Management in Small and Medium-Sized Enterprises
}

\author{
Dr. Josephine K. Nsubuga-Mugoa ${ }^{1}$, Dr. Irene A. Williams ${ }^{2}$ and Dr. Jorge Gaytan ${ }^{2}$ \\ ${ }^{1}$ Member, The National Society of Leadership and Success, Walden University \\ ${ }^{2}$ Senior Contributing Faculty, College of Management and Technology, Minneapolis, Walden University, USA \\ *Correspondence: Dr. Josephine K. Nsubuga-Mugoa, ikn.mugoa@gmail.com
}

\begin{abstract}
The purpose of this multiple case study was to explore strategies that managers of small and medium-sized enterprises (SMEs) use to effectively integrate knowledge management (KM) into business practices. The study population comprised of five managers from two SMEs operating in Uganda. The eligibility criteria were that participants had to be managers from Ugandan SMEs with a knowledge-intensive environment, with some responsibility of KM in the organization, and experienced with at least 1 year of successful KM practices. The conceptual framework for this study was theory z. Data were collected through face-to-face, semi-structured interviews, and reviews of company documents. Member checking was completed to strengthen credibility and trustworthiness.
\end{abstract}

Synthesis: After methodological triangulation of the data sources collected and completion of Yin's 5-step process of data analysis, five themes emerged: having supportive leadership, ensuring sustainability, embedding KM practices in the organization culture, socialization, and embracing modern technology. The findings of this study might promote social change by supporting small and medium-sized enterprise (SME) managers' use of KM to expand opportunities for employees to learn new skills and knowledge leading to the expansion of employment opportunities.

KEYWORDS: Enterprise social media, Familyism, Institutional theory, Management research, Socialization, Theory z, Transaction cost theory

\section{ARTICLE INFORMATION}

Author(s): Dr. Josephine K. Nsubuga-Mugoa, Dr. Irene A.

Williams and Dr. Jorge Gaytan

Received: 13 Aug, 2021; Accepted: 14 Sep, 2021; Published: 30 Sep, 2021;

e-ISSN: 2347-4696;

Paper Id: BMN-IJBMR-2021-62;

Citation: doi.org/10.37391/IJBMR.090313

Webpage-link:

https://ijbmr.forexjournal.co.in/archive/volume-9/ijbmr-090313.html

\section{INTRODUCTION}

Knowledge management (KM) is vital in an organization for strategic and theoretical reasons [1]. However, despite the potential benefits of KM, managers in developing countries rarely use $\mathrm{KM}$ in their workplaces [2]. Lee, et al. [3] found that of the SMEs in Malaysia, a developing country, $22.1 \%$ spend nothing, and $27.7 \%$ spend less than 1000 Ringgit (\$230) on KM per annum. The specific business problem is that some small and medium-sized enterprise (SME) managers in Uganda lack strategies to effectively integrate KM into their business practices.

Business leaders should be on the lookout for opportunities that lead to innovativeness and competitiveness in their businesses. Knowledge management (KM) has a direct positive and significant relationship with both technological innovation and competitive advantage [3]. Hsieh, et al. [4] recommended that researchers should carry out further research on the influence of KM to support business strategy, intellectual capital, decision-making, knowledge sharing, organizational learning, innovation performance, productivity, and competitive advantage. The use of $\mathrm{KM}$ practices can contribute to the overall growth of small and medium-sized enterprises (SMEs) by simultaneously and significantly enhancing their performance [5]. Perez-Soltero, et al. [6] noted that, in the implementation of KM strategies in SMEs, there is a gap in understanding how these strategies allow improvements in the development process of the areas involved in them. In this study, we explored the KM strategies that SMEs may integrate into their business practices for competitiveness.

Uganda is one of the leading entrepreneurial countries in the world with the majority of its business ventures in the category of SMEs [7]. SMEs have special challenges and factors that affect their business success, and many SMEs do not reach their full potential and fail to grow, leading to loss of jobs and wealth for the areas in which they operate [8]. Innovation fully mediates the relationship between $\mathrm{KM}$ and the business performance of SMEs [8]. KM as a concept is important due to the growing awareness of the importance of knowledge for organizations' prosperity and survival [8]. Durst and Edvardsson [9] recommended that future researchers should take a few factors into account. These factors are that SMEs are not comparable to large listed firms, and researchers should thus disengage from discussing KM in SMEs from a large firm perspective and use a more realistic approach by taking into consideration the resource constraints SMEs face and the environments in which they operate [9]. In this study, we explored the KM strategies that SMEs use to overcome some of the resource constraints.

The target population for this study consisted of managers in two SMEs in Uganda who had the experience of successfully integrating $\mathrm{KM}$ into their business practices. The research 
question for this study was:

What strategies do some SME managers in Uganda use to effectively integrate KM into their business practices?

The conceptual framework of this study was theory $\mathrm{z}$ [10]. Theory $\mathrm{z}$ is an enhancement of McGregor's [11] behavioral X and $\mathrm{Y}$ approach [12]. Researchers and practitioners apply theory $\mathrm{z}$ to promote high productivity, partnership, trust, and teamwork [13]. Ouchi [14] explained that a variety of social mechanisms reduce differences between individual and organizational goals and produce a strong sense of community. The strong sense of community leads to a set of traditions in a formal organization that may produce a unified, although implicit philosophy, functionally equivalent to a theory about how that organization should work [14]. A disruption of the socialization process will inhibit the passing on of traditions and bring about organizational inefficiency [14]. The theoretical concepts in theory $\mathrm{z}$ provided a suitable theoretical lens that we used to study the KM strategies that SME managers use.

\section{MATERIALS AND METHODS}

In this study, we used the qualitative research method. The qualitative method was suitable for this study because we had to produce a thick description of the phenomena under study, which are the strategies that managers in Uganda use to integrate $\mathrm{KM}$ into their business practices. We collected data by conducting face-to-face semi-structured interviews, recorded them using a digital audio device for each participant, followed by member checking, documentation review, and direct observations at the companies' premises.

\subsection{Research Design}

We used a multiple case study design. Researchers use the multiple case study design to reinforce the credibility, dependability, confirmability, and transferability of a study $[15,16]$. Yin [17] explained that analytical conclusions, independently, arising from two cases or more will be more powerful than those from a single case. We used the multiple case study design to explore successful strategies that SME managers use to integrate $\mathrm{KM}$ into their business practices.

\subsection{Data Saturation}

As researchers discuss the research design, they should also consider the approaches that they will use to reach data saturation. Morsink, et al. [18] reached the point of data saturation when they could not identify any new themes in four consecutive interviews. To determine that we had reached the data saturation point we continued interviewing participants and probing further until we were no longer able to identify any more new themes.

\subsection{Population}

In this qualitative multiple case study, the target population comprised of managers from two Ugandan SMEs with successful experience in KM implementation. For the successful management of population sampling in qualitative research, researchers intentionally select and delineate participants that would best enrich the research study [19]. In this qualitative study, our objective was to explore the KM strategies that SMEs use to integrate KM into their business practices successfully, hence, we targeted SMEs managers with experience in KM implementation.

\subsection{Sampling Design}

Researchers may use various sampling methods that include census, convenience, purposive, criterion, or the snowball methods. We used purposive sampling to be able to understand the integration of KM into business practices. Yin [17] posited that if the researcher's objective is to gain insights or a deeper understanding of an event or setting, then purposeful sampling is a suitable approach to maximize the collection of contextually rich data. For this research study, we used purposive sampling to get a deeper understanding of the different strategies that SME managers use to integrate $\mathrm{KM}$ into their business practices successfully.

\subsection{Sample Size}

There are different strategies for purposive sampling. Onwuegbuzie and Leech [20] pointed out that one of the sampling decisions that researchers should make is selecting an appropriate sampling strategy. The strategies researchers may employ to get a suitable sample size include parallel, nested, and, or multilevel strategy [20]. To get a suitable sample size for this study, we employed the nested sampling approach shown in Figure 1.

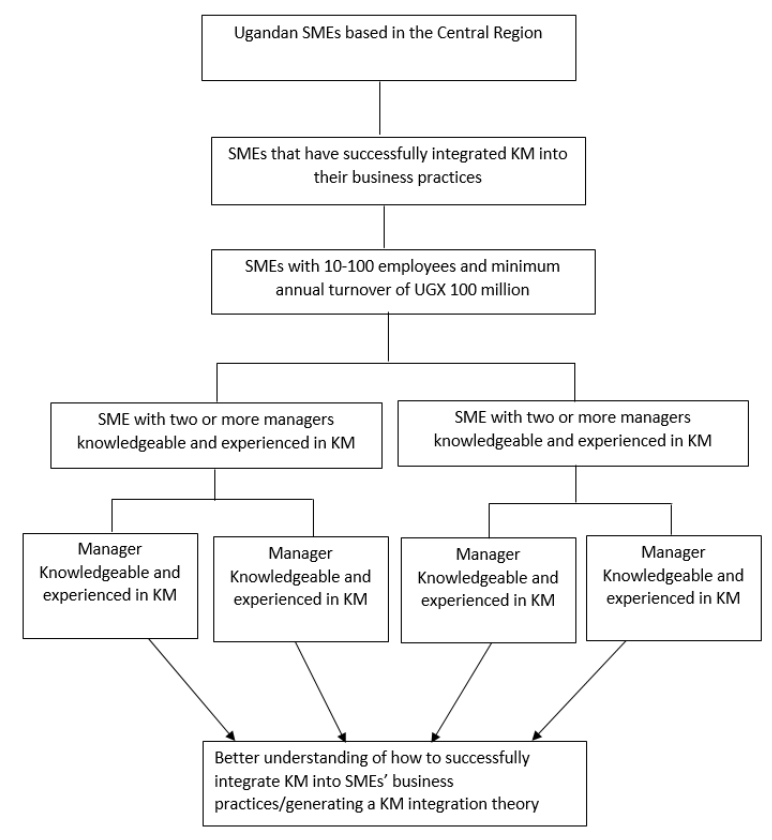

Figure 1: Sampling design chart.

\subsection{Data Collection Instruments}

We were the primary data collection instrument. Qualitative researchers are the primary data collection instrument and must take steps to ensure the trustworthiness of the data while in the field $[21,22]$. The other data collection instruments that 
we used are semi-structured interviews, review of organizational documentation, and observations. Qualitative researchers frequently use interviews as a primary source of data because it is a natural approach to the inquiry and serve as one of the most important sources of evidence in a case study $[17,23,24]$. We interviewed participants by using a semistructured interview protocol with open-ended questions (see Appendix A). We abided by the interview protocol, asked questions to each participant without bias, and used unobtrusive recording devices to audio record the interviews.

Researchers when interviewing may also ask participants probing questions. Good probing is an effective interview technique and the semi-structured interview protocol approach gives the interviewer the freedom to probe further within a particular subject area and to word questions spontaneously while keeping a focus on that area $[25,26]$. We added probing questions whenever we identified a need during the research study and as we interviewed the participants.

We also collected data by examining public documents of the organizations that included management reports. We examined internal working documents that participants availed us, that included, stock registers, customer diaries, job cards, minutes of meetings, circulars, quotations, local purchase orders, and letters of correspondence or e-mails. One of the principles of data collection is for the researchers to use multiple sources of evidence [17]. We used data triangulation and member checking to enhance the reliability and validity of the data process. Under data triangulation, researchers collect information from multiple sources but aiming at corroborating the same finding [17, 27]. We reviewed publicly available documents and those that the organizational leaders provided.

We used member checking to validate our interpretation of participants' responses to interview questions by giving these interpretations back to the participants and asking them to validate their responses. Yin [17] pointed out that a major strength of case study data collection is the opportunity to use many different sources of evidence. Before leaving any site of the interview, we validated the information we received with each interviewee and made an appointment to go back for member checking. We also shared our preliminary findings with at least two other colleagues to validate our findings.

\subsection{Data Collection Technique}

We collected data using multiple sources of evidence. Researchers use multiple sources of data to contribute to the trustworthiness of the data and the methodological rigor of the study [28]. The main advantage of using multiple sources of evidence is to allow researchers to develop converging lines of inquiry and enhance the construct validity and reliability of the study [17]. Researchers use multiple raters, among which are peers, and multiple sources of data, among which are interviews, documents, reports, and surveys, to enable increased reliability and convergent validity to overcome the possible shortcomings of self-report [29, 30]. As per the IRB guidelines, researchers should provide the steps he or she will follow to obtain existing data or contact information of potential participants, informed consent procedures, description of any pilot activities and data collection steps, and transcript review or member checking. We gained access to the participants from whom we collected the data, by first contacting the leaders of the SMEs to seek their willingness to provide a letter of cooperation granting permission for access to all relevant data, participants, facility use, and use of personnel time for research purposes. In this study, to maintain a chain of evidence, we used research logs, reflective journals, maintained case study databases, and three electronic devices to record the interviews.

\subsection{Data Organization Technique}

We organized or classified the data into different themes. Researchers classify data to enhance the readability of data, to easily study the data characteristics, to strengthen data control, and to accord meaning to the data [31-33]. We assigned different codes to identify the different themes. We used a Microsoft Excel spreadsheet to classify data themes, code, and analyze data; maintain and store the codes and themes electronically. We organized the themes into sections using a matrix-like structure used for pattern matching. We used research $\operatorname{logs}$ to record field notes immediately after each interview and maintained and stored the research logs in a Microsoft Excel spreadsheet.

\subsection{Data Analysis}

Once researchers are through with collecting and validating the data, the next step is to analyze them. Data analysis involves organizing, examining, categorizing, and tabulating the data, with the aim of exposing ideas that answer the central research question [17, 34]. Data analysis takes place in two phases, primary and secondary. Primary data analysis involves identifying themes and patterns within each category found in the interview transcripts; that is using the data that the researchers directly collected [35]. Secondary data analysis involves identifying, corroborating, contradicting emerging themes and patterns in the documents, and testing several combinations of tools and parameters [36]. A discussion of the methods and tools we used to analyze the data we collected for this study, follows.

Researchers employ triangulation methods to carry out the data analysis. The five triangulation types are: (a) data triangulation, (b) investigators triangulation, (c) theory triangulation, (d) methodological triangulation, and (e) philosophical triangulation, which is outside the scope of this study [37]. In this research study, we employed methodological triangulation.

There are two methodological triangulation approaches. Methodological triangulation may either be within-method or between or across-method [38]. In this qualitative multiple case study, we employed the within-method methodological triangulation to analyze the data. The analysis process that researchers may employ is in five steps: (a) compiling, (b) disassembling, (c) reassembling, (d) interpreting the meaning of, and (e) concluding the data [17, 39]. In the following 
paragraphs, we discuss how we employed each of these steps in triangulating and analyzing the data.

\subsection{Compiling the Data}

Researchers should put the data they collected in a particular order to be able to analyze it well. The process of compiling is gathering and organizing the data that researchers collected, that is retrieving and tallying specific words and terms from the researchers' notes to find meaningful answers to the research question $[17,39]$. We transcribed all the recordings of participants' interviews and recorded the notes from observations, examinations, and reviews of the organizations' documentation, in a Microsoft Excel spreadsheet.

\subsection{Disassembling Data}

After compiling the data, the next step is to disassemble the data. Disassembling entails a proper procedure of coding data, by the researchers moving methodically to a higher conceptual level of assigning codes to like words and terms [17]. Themes emerge from keywords and patterns when researchers disassemble the data [40]. Color coding is a useful feature in helping to find patterns and relationships in the data, develop themes, and to highlight critical or to elevate results [41-43]. We used a Microsoft Excel spreadsheet and color-coding to organize the data into categories, label each category into themes, and code them.

\subsection{Reassembling Data}

From disassembling, the researchers reassemble the data. In the reassembling stage, researchers interpret the relationships among codes, their combinations, and conceptually higher patterns, identifying themes and patterns [17, 44]. We analyzed the data to extract the themes that directly or indirectly helped us to answer the research question.

\subsection{Interpreting the Meaning of the Data}

Before researchers present their findings, they should interpret their findings. Researchers interpret data in a way that aligns with the method of the research study. Dillaway, et al. [45] asserted that the qualitative approach to interpreting and analyzing data involves interpreting words, not numbers. We made interpretations and related them to the central research question, taking into consideration that all the themes should exhaustively help to answer the central research question. We analyzed and interpreted the data in line with the conceptual framework and ensured that the findings of the study correlated in providing successful strategies that SME managers may use to integrate $\mathrm{KM}$ into their business practices.

\subsection{Concluding the Data Analysis}

Researchers should conclude the data analysis. Researchers should give clear-cut conclusions that they have drawn from their multifaceted analysis and yield results that are open for scrutiny into the researchers' decision making throughout the analysis process $[39,46]$. We drew from our findings and interpretations and suggested a model that managers of SMEs may use to come up with successful strategies that may help them to integrate $\mathrm{KM}$ into their business practices successfully.

\subsection{Reliability}

We followed the interview protocol (Appendix A) to interview all the participants in the study, asking each participant the same open-ended questions. Researchers may transcribe and analyze interviews using coding and thematic analysis [47]. Researchers may then carry out member checking. After conducting the interviews, we immediately transcribed the audio responses into Microsoft Excel spreadsheet, then we reviewed, analyzed, and identified themes from each transcript to make meaning out of the responses. To ensure reliability, we carried out member checking with each participant. After carrying out the interviews, we immediately shared our findings with and received feedback from two colleagues to test the accuracy of the findings.

\subsection{Validity}

Researchers should ensure that the participants of the study agree with the findings. Researchers should also verify their findings before concluding the study. Forman, et al. [48] asserted that member checking is a well-established way to evaluate credibility. One of the strategies of increasing the credibility of research is triangulation [49, 50]. Data triangulation helps to strengthen the construct validity of the case study [17]. We used member checking and triangulation to ensure the credibility of our findings.

Another check for the credibility of the study is transferability. It is the qualitative inquirer's role to provide thick descriptions of the study to enable future researchers to determine its transferability [51]. During the interviewing process, we gathered as much information as possible from the participants that enabled us to provide thick descriptions of the findings to enable future researchers to determine transferability.

Researchers should also consider confirmability. Researchers may achieve confirmability of qualitative inquiry by using an audit trail, reflective journals, and triangulation [51]. During the data collection process, we used reflective journals to ensure capturing all the necessary details before leaving a particular point of the interview and made use of research logs to maintain a chain of evidence for audit purposes. We also used data triangulation by using multiple sources of data which included: (a) interviews, (b) observations, (c) company websites, and (d) examining and reviewing available documents, while noting information relevant to our research study.

We reached data saturation when we obtained no new information from the data collected and when further coding was no longer feasible.

\section{RESULTS}

The overarching research question for this qualitative multiple case study was: What strategies do some SME managers in Uganda use to effectively integrate KM into their business practices? We used semi-structured interviews and archival 
documents that included customer warrant cards, stock registers, local purchase orders, job cards, diaries, organization charts, financial audit reports, and management meeting minutes for methodological triangulation. We interviewed five managers from two SMEs located in central Kampala. We interviewed participants using ethical consideration and responsibility and adhered to The Belmont Report protocols [52]. We followed an interview protocol to interview the participants.

Using theory $\mathrm{z}$, we were able to explore the strategies that some SME managers in Uganda employed to effectively integrate $\mathrm{KM}$ into business practices. We found theory $\mathrm{z}$ a suitable framework to understand the findings of this inquiry. We used Yin's [17] five-step process consisting of (a) compiling, (b) disassembling, (c) reassembling, (d) interpreting, and (e) concluding the data to analyze the responses of the interviewees, our field notes, reports, minutes, and day-to-day operational forms that participants availed us.

\subsection{Demographic Information}

Both SMEs we used in this study had been in existence for more than 5 years, employed 10 or more employees, and had an annual turnover above UGX 100 million. The participants provided answers to the demographic questions addressing the job title, duties or responsibilities in the organization in which the participant was involved, the number of years of experience in the current role, and their specific responsibilities. Three of the participants had never worked in any organization other than the current one. The participants held leadership positions within their departments, and their years of experience ranged from 1 to 26 years. Table 1 shows the details of each of the companies we used in this study, and Table 2 shows the demographic information of the participants. To maintain confidentiality, we assigned a unique code to each of the five participants.

\begin{tabular}{|l|c|c|c|c|}
\hline Company & $\begin{array}{c}\text { Years in } \\
\text { existence }\end{array}$ & $\begin{array}{c}\text { Annual } \\
\text { turnover } \\
\text { (UGX } \\
\text { Billion) }\end{array}$ & $\begin{array}{c}\text { No. of } \\
\text { employees }\end{array}$ & $\begin{array}{c}\text { Employees } \\
\text { at } \\
\text { managerial } \\
\text { level }\end{array}$ \\
\hline $\begin{array}{l}\text { Company } \\
\text { X }\end{array}$ & 26 & 1.30 & 20 & 6 \\
\hline $\begin{array}{l}\text { Company } \\
\text { Y }\end{array}$ & 6 & 0.12 & 12 & 5 \\
\hline
\end{tabular}

Table 1: Description of SMEs.

\begin{tabular}{|l|c|c|}
\hline Participant & $\begin{array}{c}\text { Years in the } \\
\text { company }\end{array}$ & $\begin{array}{c}\text { Managerial experience } \\
\text { (years) }\end{array}$ \\
\hline N1 & $1-2$ & $1-2$ \\
\hline T2 & 6 & 2 \\
\hline B3 & 6 & 6 \\
\hline M4 & 26 & 26 \\
\hline F5 & 6 & 6 \\
\hline
\end{tabular}

Table 2: Participants' demographic information.

\subsection{Triangulation}

The triangulation process included responses from the interview questions, the company's archived documents, information from company websites, and observations at the company premises. The company's archived documents included audited accounts, job cards, organization charts, stock register, quotations, local purchase orders (LPOs), management meeting minutes, customers' diaries, and company websites. The information we observed on company websites included various products and services offered by the SMEs. Our observations at the premises relevant to this study were the desktops, the laptops, photocopiers, filing cabinets and files, storeroom, equipment for sale on display, and other employees at the premises who were not participants in the study.

\subsection{Findings Details}

Five themes emerged, during data analysis, to answer the research question. By coding and employing the theory $\mathrm{z}$ lens and using color-coding, we identified key phrases and grouped the keywords to form different categories or subthemes that emerged into the five main themes. Table 3 includes the number of participants whose responses led to a particular subtheme to emerge under each main theme.

\begin{tabular}{|c|c|c|}
\hline Main theme & Subtheme & $\begin{array}{l}\text { Number of } \\
\text { participants }\end{array}$ \\
\hline \multirow[t]{5}{*}{ Supportive leadership } & Communication & 3 \\
\hline & Decision making & 3 \\
\hline & Monitoring \& control & 4 \\
\hline & Support employees & 4 \\
\hline & Exemplary Leader & 4 \\
\hline \multirow{4}{*}{$\begin{array}{l}\text { Ensuring } \\
\text { sustainability }\end{array}$} & Training and learning & 4 \\
\hline & Quality & 3 \\
\hline & Motivating employees & 4 \\
\hline & Routines & 5 \\
\hline \multirow{7}{*}{$\begin{array}{l}\text { Embed KM practices } \\
\text { into organization } \\
\text { culture }\end{array}$} & Knowledge discovery & 3 \\
\hline & $\begin{array}{l}\text { Acquisition, retention } \\
\text { and protection }\end{array}$ & 4 \\
\hline & $\begin{array}{l}\text { Dissemination and } \\
\text { sharing }\end{array}$ & 3 \\
\hline & Teamwork & 3 \\
\hline & Communication & 2 \\
\hline & Commitment & 2 \\
\hline & Familyism & 2 \\
\hline \multirow[t]{3}{*}{ Socialization } & Teamwork & 3 \\
\hline & Social networks & 3 \\
\hline & Familyism & 2 \\
\hline \multirow{5}{*}{$\begin{array}{l}\text { Embracing modern } \\
\text { technology }\end{array}$} & The customer & 3 \\
\hline & Limit cost & 2 \\
\hline & KM practices & 4 \\
\hline & $\begin{array}{l}\text { Marketing products and } \\
\text { services }\end{array}$ & 3 \\
\hline & Networking & 2 \\
\hline
\end{tabular}

Table 3: Number of participants per subtheme for each main theme. 


\section{Theme 1: Having Supportive Leadership}

The first theme that emerged from data analysis was having supportive leadership. Within Theme 1, we identified five subthemes: communication, decision making, monitoring and control, supporting employees, and exemplary leader. Communication emerged from the participants' responses as a factor that contributed to employees' commitment and proper $\mathrm{KM}$ practices in an organization. The participants' responses indicated that communication made a contribution to sharing and discovering knowledge, motivating employees' commitment to perform and, in some companies, becoming part of the company culture.

Participative decision making also emerged as one of the factors that motivated employees to perform. From the participants' responses and what we noted from the company minutes, managers involved employees in making decisions through departments and holding meetings. From the minutes, we noted that members gave priority to the informed position, decisions, and planning on the weekly report agenda. Regular monitoring featured as one of the ways managers ensure that employees adhere to KM practices. Through monitoring and control, the managers kept in touch with their subordinates, supported them whenever a need arose, and kept in touch with and made the customers happy.

Basing on the participants' responses, employees do their best if the leaders are always there to understand and support them. From the findings of this study, leaders of organizations should be exemplary in what they do, as exemplary leaders impact the people they lead. The leaders of the companies exhibited commitment in their work, and this motivated their managers to perform. The implication here is that managers should work with their subordinates to give them timely support.

We found that the leaders of the organizations were in touch with the employees through good communication and leading by example, involved their employees in decision making to motivate them to perform effectively, supported them to carry out their duties and ensured that they fit well into the working environment. Leaders also made changes in the work that each individual performs when they found it necessary. SME leaders remained in control through monitoring and holding regular meetings and checking on progress.

Theme 1 linked well with the literature, in line with leadership direction to employees, communication, participative decision making, and employee-supervisor relationship. For example, leadership is a key factor in determining the successful implementation of knowledge retention among SMEs [53]. From the study, we found that SME leaders involved subordinates in decision making leading subordinates to feel involved and supported. Theory z-type companies commit to participative decision making to recognize individual and group needs and simultaneously develop exceptional quality control techniques and scientific work methods [12, 54]. Leaders should have mixed leadership qualities that enable them to control and support the performance of their employees.

\section{Theme 2: Ensuring Sustainability}

The second theme that emerged from this study was ensuring sustainability. Four subthemes emerged within Theme 2. We found that to sustain KM in business practices, managers were keen on (a) training and learning, (b) quality, (c) motivating employees, and (d) routines. SME managers carried out training and learning in different forms, frequently, and continuously. We also found that leaders were mindful of the quality of employees they hire and of the work employees produce. We found that leaders motivated employees to perform well by offering incentives and involving employees in decision making. Another finding was that leaders ensured that they maintained the activities and processes that supported $\mathrm{KM}$ practices as routines.

Training and Learning: We found that certain aspects of the training were continuous and these included: (a) on the job training, (b) skills and knowledge dissemination, (c) training backup workforce, (d) orientation, (e) organized staff training, and (f) studying and understanding competitors. We noted that if leaders provide for a backup workforce, they would indirectly encourage managers and other employees to share their knowledge and skills with their colleagues, then, training and learning would be part of the day-to-day activities within the company.

Quality: We found that managers were mindful of the quality of professionals they took on board and of knowledge that they documented. Participant B3 explained that they quantified each activity and weighed the value addition and whatever activity that SME managers could not quantify was work not done. Participant F5's focus was on the quality of a new employee joining the company. F5 pointed out that it was the company's policy to interview any new person coming on board and to find out the value the new employee would add to the company. Participant T2 indicated that a new person coming on board had to qualify as a technical person to take up the position of a technical manager. Both F5 and T2's focus was on the quality of professionals that join the company.

Motivating Employees: We found that SMEs leaders motivated employees to perform by providing (a) incentives and rewards, (b) salary increments, (c) involvement in decision making (d) favorable working environment, and (e) work upgrades. We noted that the salary increases were incentives in the form of commission or bonus and salary increments. About decision making, we noted that some SMEs leaders involved concerned employees in deciding upon certain issues concerning the company and negotiated with them on the way forward. The indication is that leaders of organizations should put systems in place that may foster the process of upgrading employees' responsibilities and provide training opportunities as a way of maintaining the employees' motivation.

Routines: Lastly under Theme 2, we found that managers carried out some routines that helped them to sustain the KM 
practices. The routines we identified included: (a) documenting, (b) recording, (c) reporting, (d) meeting, and (e) replicating. Four of the participants indicated that these activities and processes were done and maintained repeatedly as routines in their companies.

From the literature, researchers valued quality both in terms of knowledge and individual employees; motivating employees to perform well; and routines that guide future behavior. Under Theme 2 we found that training, quality, motivation, and routines were the factors that contributed to the sustainability of KM practices. We found that to sustain both tacit and explicit knowledge, the leaders of the companies promoted continuous training and learning and were also mindful of the quality of knowledge that they acquired and the quality of knowledge workers that they brought on board.

Theme 2 aligned with the conceptual framework considering that under theory $\mathrm{z}$, the emphasis for sustainability is on trusting employees. Organizations trust workers to do their jobs to their utmost ability and managers look out for employee wellbeing, which serves as motivation to the employees [55]. One of the features of theory $\mathrm{z}$ is skills training [56]. From the study, we found that continuous training and learning of employees to acquire new skills was crucial to sustain the practices of KM.

We found that the factors that motivated employees included incentives and rewards in the form of commission and bonus involvement in decision making. Ouchi [57] established that employee motivation factors include (a) incentives and rewards, (b) recognition, (c) organizational value, (d) team building, (e) involvement in decision making, and (f) time management. The findings from this study did not bring out team building and time management. Ho, et al. [58] posited that theory $\mathrm{z}$ organizations should instil some degree of discipline in the form of procedures and work instructions and develop self-discipline and self-confidence. Ouchi refined McGregor's [11] theory and found that self-discipline was important for organizational success. We found that the routines that the SMEs leaders sustained were meeting, documenting, recording, and replicating. The implication is that leaders of organizations should develop self-discipline to be able to sustain the various routines necessary to contribute towards KM implementation.

\section{Theme 3: Embed Knowledge Management Practices in the Organizational Culture}

The third theme that emerged from the data analysis was embedding KM practices in the organizational culture. The practices that emerged were (a) knowledge discovery; (b) acquisition, retention and protection; and (c) dissemination and sharing. Also, subthemes that supported the KM practices emerged as (a) communication, (b) teamwork, (c) commitment, and (d) familyism.

Knowledge Discovery: From the study, knowledge discovery emerged as one of the KM practices that helped leaders perform well. Participant B3 emphasized that consistently carrying out good practices and repeating them, as needed, helped in discovering knowledge; and that replicating the good practices and discovering new ways of working, was part of the company culture. B3 further added that with constant training and communication, knowledge discovery became part of the company's day-to-day accomplishment, and management strived to discover new knowledge from the new staff to create a learning environment. Other participants' responses indicated that through training they discovered new knowledge that they shared with the rest of the employees and used it to move the company to higher levels.

Acquisition, Retention, and Protection: Under acquisition, retention, and protection, four of the participants indicated that they carried out documenting, recording, filing, and continuous training and learning with ease; an indication that such practices were already part of the culture of the companies from which we recruited participants. Participant T2 maintained a record of customer complaints and challenges about any equipment that customers purchased. The implication was that, in the future, if customers report similar complaints, the record would be handy to be referred to by technical staff to attend to such similar complaints. Participant F5 used e-mail or WhatsApp to share information and documents, Dropbox or iCloud to save documents, passwords to protect or limit access to important information, and filed hard copies of any important information or documents as a backup. F5 kept all important information in cyberspace to ensure that there is no loss of such important information or documents and to enable accessibility of that information from anywhere and at any time. The use of modern technology emerged as a tool that helped managers in the process of acquisition, retention, and protection of knowledge. F5 emphasized that training and learning was a core value of the company. We found that managers valued learning and constantly documented lessons learned for future reference.

Dissemination and Sharing: Another subtheme that emerged was dissemination and sharing. There was a similarity between our findings for this subtheme and those under the acquisition, retention, and protection category. Training, learning, and mandatory documentation also emerged in this category. The new practices that emerged were role sharing, segregation of duties, and transparency. We found that managers motivated new employees to share knowledge by themselves setting an example of sharing their knowledge with the new employees through orientation programs.

We found that familyism, commitment, teamwork, and communication were factors that supported KM practices to take root in the companies from which we recruited the participants for the study. Company leaders decentralized the dissemination of information, as one participant pointed out that dissemination of information sometimes took place through departmental managers. We found that the participants' focus in employing the different factors that support KM practices varied from one participant to another. Participant B3's focus was towards teamwork and commitment, F5's towards teamwork and communication, and 
M4 focused on all the four factors: teamwork, commitment, familyism, and communication.

The findings we noted under Theme 3 aligned with various findings from previous studies. Mohapatra et al. (2016) found that the more an organization embeds $\mathrm{KM}$ in its culture, practices, and processes, the more successful it will be in implementing the KM strategies. In line with the supporting factors, El Khouly and Fadl [59] found that commitment was one of the cultural dimensions that have high significance on work quality. We found that leaders of the companies motivated employees to ensure that the employees remained committed to performing to their best. Leaders valued treating their employees as family members to motivate them to remain in the company for a long period. We found that SME managers took on KM practices as part of the daily routines of their companies and in turn supported the employees to remain committed to their duties.

The findings under Theme 3 match the conceptual framework concepts. Benton and Magnier-Watanabe [60] basing on theory $\mathrm{z}$ found that the sharing of knowledge internally, partly due to long-term employment practices and common cultural values that organizations develop through long-term employment, was likely to promote greater organizational commitment among employees. Theory $\mathrm{z}$ relates to the way the organizational culture affects the entire organization regarding management and organizational behavior [56]. We found that SME managers took on KM practices as part of the daily routines of their companies and, in return, the process helped the employees to show commitment to their duties. The application of theory $\mathrm{z}$ leads to the promotion of high productivity, partnership, trust, and teamwork [13, 61]. By applying supportive factors of familyism, commitment, teamwork, and communication, leaders held trust and togetherness among employees and achieved the set goals as a team.

\section{Theme 4: Socialization}

Another theme that emerged from data analysis was socialization. Within the socialization theme, we identified three subthemes from conducting semi-structured interviews with the five participants. The three subthemes included teamwork, social networks, and familyism. We found that teamwork and familyism crosscut between Theme 3 and Theme 4. Teamwork and familyism emerged as supporting elements under Theme 3 and as core aspects of Theme 4 .

Teamwork: The codes that emerged under teamwork included participative decision making and supporting and standing in for one another. Participant B3 stated that every Monday the management team and its subordinates held meetings where they made decisions that affected the company and agreed on how to proceed to enact changes. A copy of the minutes that one of the participants availed us supported B3's statement of holding meetings and making decisions. Participant F5 explained that the management team involved employees in decision making and negotiated with employees the way forward. We observed, at one of the companies, that there was no special place for the leader of the company, as the leader of the company, shared an office and a table with other employees. Participant M4 indicated that working as a team helped managers to attend to the challenges each employee or department faced and fostered togetherness and harmony among the employees.

Social Networks: Managers and their subordinates used social media enterprises as one of the ESNS paths to integrate KM into their business practices. One of the participants explained that employees socialized through a WhatsApp group that the employees created to (a) share challenges and helped one another to solve any problems that arose, (b) develop new and innovative ideas that may take the company forward, and (c) receive encouragement to look ahead. Another participant posited that through WhatsApp, managers kept track of all employees' communication that went on, and were able to act on issues that needed attention promptly. One participant stated that many people communicated to the company through Facebook. Through social networks, like WhatsApp and Facebook, managers were able to keep track of discussions that went on among the employees, learned their concerns, and addressed them promptly. Through social networks, managers kept in touch with people outside the company, got feedback, and obtained new ideas that helped managers to serve their clientele better.

Participant B3 indicated that social networks, especially WhatsApp, helped the company not only in networking but also in the day-to-day operations, adding on that writing on paper was not their strength. We confirmed that one of the companies ran a mostly paperless office as most of the documents we asked to review were provided as soft copies. Participants M4 and F5 also indicated that they participated in external networks as a way of enriching the knowledge in their respective fields of operation and tapping opportunities that existed outside the individual companies. Some of the external networks that participants mentioned included, Uganda National Chamber of Commerce (UNCC), Uganda Manufacturers Association (UMA), Uganda National Scales and Technicians Association (UNSTA), and Kampala City Traders Association (KACITA). Participant M4 explained that through such networks they remained competitive in producing quality products, got exposed to new clients and new information, carried out joint ventures, like tours, and fought for their rights as business people.

Familysim: We found that familyism contributed to socialization. Participants indicated that company leaders treated employees as a family and employees treated each other as family, and both leaders and employees treated a new person in the same way. Participant F5 mentioned that there was an integrated package for the employees that included getting a driving permit, health insurance, and passport. F5 also mentioned that management hold staff parties as one of the ways used to keep employees motivated to work together. In support of familyism, participant M4 stated that employees would leave the company if not treated like family. The 
implication is that if company leaders promote familyism they would maintain a low staff turnover in the company.

Theme 4 aligned with other researchers' findings in various aspects. Ogbu and Oaya [56] found that through the process of socialization, managers influenced and determined employees' outlooks, viewpoints, outputs, attitudes, and behaviors. Fang, et al. [62] showed that through socialization, managers could motivate employees to perform by emphasizing participative decision making. We found that leaders involved employees in decision making and employees were motivated to perform since they contributed to the final decisions.

Socialization is one of the theoretical components of theory $\mathrm{z}$. Theory $z$ proponents are concerned with human resources, and one of the three interrelated strategies that theory $\mathrm{z}$ proponents employ is intensive socialization [56]. We found that managers promoted teamwork among employees and teamwork helped managers to set priorities that everyone owned. Second, we found that managers work with other employees without boundaries, and when challenges arise, they support one another. The findings aligned with Ouchi's [14] statement that a variety of social mechanisms reduced differences between individual and organizational goals and produced a strong sense of community, but a disruption of the socialization process inhibited the passing on of traditions and brought about organizational inefficiency.

We found that leaders of the companies treated all employees as family members and employees in the same company also treated each other as members of one family. One of the characteristics of theory $\mathrm{z}$ is the holistic concern that includes family members as well [63]. From this study, we noted that managers promoted socialization to enable employees to learn from each other and to work as a family. The implication is that managers may apply socialization to easily pass on KM practices from one employee to another and from old to new employees and vice versa.

\section{Theme 5: Embracing Modern Technology}

Another theme that emerged from data analysis was embracing modern technology. Within Theme 5, we identified five subthemes: (a) attend to the customer, (b) limit costs (c) carry out KM practices, (d) market company products and services, and (e) engage in networking. In the following subsections are the details of our findings.

The Customer: Participants' responses to the open-ended questions during the semi-structured interviews focused on the customer. Three of the participants explained that they used modern technology to support the process of integrating KM into business practices and the process impacted the customer to the benefit of their companies. Participants indicated that managers and employees used IT as support to (a) increase the number of customers, (b) expand the customer base, (c) retain the customers, (d) satisfy the customer, (e) win customer trust, and (f) make the customer happy. Participant B3 explained that online marketing was an asset to the company and that the company made sales to customers from other areas, including Kenya, Southern Sudan, and Rwanda. We found that with the aid of modern technology, managers made sales and customers made purchases in a purely virtual environment, and yet both parties remained happy and satisfied.

Limit Costs: We found that managers used desktops, laptops, accounting packages, word processors, smartphones, ESNS, ESM, and LANs in their operations to limit costs. Participant B3 indicated that company managers maximized the use of smartphones and were able to keep tracking documentation and monitoring without spending on transport and paper. B3 further indicated that company managers made use of modern technology to minimize paperwork, maximized the use of cyberspace, WhatsApp, e-mail communication, made use of smartphones to record and send audios and to make payments. Participant F5 explained that employees shared information that needed immediate attention in the virtual space using email, social media, Dropbox, and iCloud promptly without necessarily printing it on paper. We found that through modern technology managers were able to reduce costs on paper, printing, communication, and transport. We also found that modern technology-enabled customers to make payments to the company without physically going to the company premises.

Knowledge Management Practices: Four of the participants indicated that they used modern technology to support the implementation process of KM. Participant M4 explained that the company had a LAN system in place that managers and employees made use of to communicate with each other from time to time, through e-mail. Participant T2 pointed out that it was a company policy for all employees to keep all paperwork in soft copy as well. Participant T2 explained that customers sent their complaints directly to the technicians by making telephone calls or by e-mail. The technicians would then record the complaints and forward them to the managers by email. Participant B3 explained that the company outsourced the services of an accountant to manage the company accounts and that there was Tally and MS Excel software in place that managers used to carry out the accounting function. Participant F5 indicated that managers used MS Excel, MS Word, and Tally software to support most of the company KM practices, which included budgeting and reporting; and as an individual was learning to use QuickBooks application for personal development. Three of the participants explained that they used e-mail and social media to share information; smartphones, laptops, and desktops as the platforms for sharing; and cyberspace for storage and protection of information and protect important documents by using passwords.

Marketing Products and Services: We found that managers used modern technology to support them in advertising and marketing of companies' products and services enabling them to trade globally from any location. Four of the participants indicated that they used ESM platforms, Facebook, WhatsApp, Twitter, and Instagram; Google; the free platforms, OLX and Jumia; and companies' websites to market and sell the companies' products. We checked the websites of the two companies whose managers participated in 
this study and verified that their products and services were well-advertised on the companies' websites. We observed that participants B3 and F5 advertised some of the companies' products and services via the status of WhatsApp. Participant N1 mentioned that people came from very far to buy the company products, because of online marketing. From this study, it was clear to us that managers used modern technology to support them in the marketing of products and services, enabling them to trade globally from wherever they may be located.

Networking: The last subtheme that emerged under Theme 5 was networking. We found that some managers used modern technology to assist them in networking. Participants T2 and F5 mentioned that they used ESM to network and smartphones, laptops, and desktops as the tools for operating ESM platforms. Participants M4 and B3 were more specific indicating that they used, Facebook and WhatsApp respectively to network.

Theme 5 aligned with some other researchers' findings in the literature. Scuotto, et al., [64] suggested that leaders of SMEs may use SMNs to form their virtual communities to achieve a common purpose and to enhance the productivity of their SMEs. Shvetsova, et al. [65] established that theory z's general availability in the era of advanced information technologies promoted social networks to occupy an important place in the life of z-generation's representative. In the future, researchers may carry out research to establish whether online marketing costs would be lower than ordinary marketing using the traditional ways of marketing, which include door to door, print, radio, and TV media advertisements; and billboards advertisements.

\section{DISCUSSION}

Knowledge has a vital role in the challenging business environment and contributes to sustaining business performance; managers of organizations should be mindful that knowledge is a crucial resource that they should manage well to help their organizations achieve growth performance [66]. The growing awareness of the importance of knowledge for the organization's prosperity and survival places KM, as a concept, at the forefront of the organizations' practices, and SMEs' innovation mediates the relationship between KM and business performance of SMEs [8]. The findings are in conformity with the three pillars of KM, that is, technology, processes, and people [67]. SMEs' managers may consider assessing their KM strategies alongside the research findings of this study under the main themes: (a) having supportive leadership, (b) ensuring sustainability, (c) embedding KM practices into organization culture, (d) socializing, and (e) embracing modern technology. Socialization and modern technology emerged as strategies that SME managers should employ to support the leadership in communication, the sustainability process, and to streamline and align the knowledge management practices into the organization's culture.
In this qualitative exploratory multiple case research study, we used theory $\mathrm{z}$ as the lens to identify the findings. The research findings aligned with the purpose of this research study. All the main themes and subthemes that emerged were crucial to the understanding of the overarching research question. This study could contribute to the understanding of the strategies and processes SME managers use to successfully integrate $\mathrm{KM}$ into business practice.

We found that a good working environment and supportive leadership helped the SME managers to perform. Second, for the sustainability of KM practices, leaders of the SMEs continuously motivated the employees through salary increments, incentives, rewards, appraisals, and training. Leaders of SMEs also continuously upgraded individual employees' working through the training, assigning multiple roles, and job rotation. Leaders also supported employees to maintain the routines of all the supporting activities that included documenting, recording, reporting, meeting and replicating good practices. Third, we found that for the proper implementation of the KM agenda SME managers embedded KM practices (a) knowledge discovery, (b) knowledge acquisition, (c) retention, and protection; and (d) dissemination and sharing in the organizational culture. Fourth, we found that SME managers promoted socialization among employees through (a) teamwork, (b) social networks, and (c) familyism and that socialization supported the embedding of $\mathrm{KM}$ practices in the organizational culture. Lastly, we found that SME managers embraced modern technology as support to (a) socializing KM practices of knowledge discovery, sharing, dissemination, retention, and protection; (b) achieving timeliness; (c) sharing marketing information; (d) widening customer base; (e) monitoring and controlling; (f) cutting down on cost for marketing, communication, and documentation; and (g) networking.

\subsection{Applications to Professional Practice}

If organizational performance improves, then, the organization becomes more credible in the community and attracts more clients. We anticipate that the findings of this study could help SME managers to put in place KM strategies for their organizations and make more informed decisions, which may help the organizations to attract more clients and improve firms' performance and profits. The findings may also motivate managers of SMEs to make use of the cheap and modern technology available to support their day-to-day operations, reduce operation and marketing costs, and adopt online marketing through sharing information online about their products and services. The finding of embracing modern technology was in line with Cerchione and Esposito's [68] findings that the technological and innovative trend in ICT was driving the development and the introduction of new KMS that availed new opportunities for SMEs that are cheaper, more user-friendly, and more effective than the traditional ways.

\subsection{Implications for Social Change}

Based on the findings of this study we noted that the study may contribute to social change in three ways. The first 
contribution is that the use of KM by managers of SMEs may expand opportunities for employees to learn new skills and knowledge and expand employment opportunities. When managers improve the performance of SMEs, more jobs and better skilled and knowledgeable people will be available on the Ugandan market. To sustain the KM practices, one of the findings from this research study was that SMEs motivated employees by treating them as a family. The second contribution towards social change that we anticipate from this research study is that SMEs' managers may learn to treat employees as family and employees will work peacefully knowing that the managers would attend to their family issues within the working family. The third contribution we anticipate is that leaders of SMEs will be more vigilant to support employees with modern technology to support the process of sharing, retention, and protection of tacit knowledge that even when an employee leaves the organization, such knowledge will remain accessible to the organization.

\subsection{Recommendations for Action}

In conclusion, we make the following recommendations to SMEs' managers for consideration. First, SMEs' managers should support employees in training, networking, and sharing of knowledge to enhance the employees' innovation skills, enabling them to discover new knowledge that may support the organization. Second, SMEs' managers should communicate freely with their subordinates and involve them in decision making. Participative decision making motivates employees to perform [62]. Involving employees in decision making contributes towards transparency, ownership, and collective responsibility in the organization and employees will trust each other as a family and feel motivated to perform. Familyism builds trust among employees and trust will influence the sharing of knowledge internally [60]. Treating employees as a family contributes to a friendly working environment.

Third, in this era of modern technology, leaders of SMEs should endeavor to construct websites for their companies to enable them to tap into the benefits of trading online. If leaders of organizations avail information, online, about the company and the products and services they offer, customers may trust that company, and trust contributes towards the company's credibility. The fourth and last recommendation is that leaders of SMEs should motivate and support their employees to access and make use of modern technology. We found that the use of modern technology-enabled SME managers to reduce operational costs, supporting cost-effectiveness. We also found that modern technology supported managers to respond to customers' needs promptly to carry out the different processes of $\mathrm{KM}$, monitoring, and controlling efficiently.

If managers of SMEs implement some of the above recommendations and follow the proposed KM framework (see Appendix B), they may successfully integrate KM into business practice and make a contribution towards the increase in the number of customers and profits, leading to productivity and business continuity. Current and aspiring SME leaders and managers interested in integrating $\mathrm{KM}$ into their business practice need to pay attention to the findings in this study. Business researchers also should pay attention to the findings.

\section{LIMITATIONS}

However, the study had two limitations. We considered only two SMEs and the potential participants were free to accept or refuse to participate in the study. The other limitation was that the two SMEs were from Kampala city. Future research should determine how these findings could be transferable to other organizations and locations. One of the findings in this research study was that managers used online marketing to do business. Participants claimed that the costs of online marketing were lower than the traditional ways of marketing which include door to door, radio and TV adverts, and street billboards. In this study, we did not specifically verify this claim. There is a need for further research to establish the relative costs of the different forms of marketing that SME managers use to market their products and services.

APPENDIX
Appendix A.: Interview Protocol
Date:
Time:
Case Classification: $\quad(\mathrm{X}, \mathrm{Y})$
Job Function: $(\mathrm{A}, \mathrm{C}, \mathrm{F}, \mathrm{H}, \mathrm{P}, \mathrm{S})$
Participant Code: $(0-9)$
Recording Method_ $(\mathrm{E}, \mathrm{M})$




\begin{tabular}{|c|c|}
\hline \multicolumn{2}{|c|}{ Interview Protocol } \\
\hline $\begin{array}{l}\text { What I will do } \\
\text { Introduce the interview and set the stage, by } \\
\text { introducing myself and asking the interviewee to } \\
\text { introduce him/herself. And answer any questions or } \\
\text { comments the interviewee may have before the start } \\
\text { of the interview. After that I will then switch on the } \\
\text { electronic device and start interviewing the } \\
\text { participant. }\end{array}$ & $\begin{array}{l}\text { What I will say } \\
\text { My name is XXXXX. Please introduce yourself as well. } \\
\text { Thank you for turning up for this interview. } \\
\text { As per what we discussed in the meeting we had earlier, I will be taking } \\
\text { you through this interview to explore the successful strategies that you } \\
\text { used to integrate KM into business practice. } \\
\text { As per my communication during the meeting and as per the consent form } \\
\text { you signed, I will electronically record all our discussion during this } \\
\text { interview. The interview will take about } 45 \text { minutes. } \\
\text { You have a right to decline participation in this interview at any time and } \\
\text { not to answer a question where you feel uncomfortable. } \\
\text { Do you have any questions or comments before we start the interview? } \\
\text { If no questions I now switch on the electronic device to start recording the } \\
\text { interview. }\end{array}$ \\
\hline $\begin{array}{l}\text { - Watch for non-verbal queues } \\
\text { - } \\
\text { - } \\
\text { Ask follow-up probing questions to get more } \\
\text { in-depth }\end{array}$ & $\begin{array}{l}\text { The Central Research Question is: What strategies do some SME managers } \\
\text { in Uganda use to effectively integrate KM into their business } \\
\text { practices? } \\
\text { Background/Profile Questions } \\
\text { First I would like you to tell me: } \\
\text { 1. What is your title and job duties/responsibilities? } \\
\text { 2. How long have you performed in this position? } \\
\text { 3. What other positions have you held in your current or other } \\
\text { organizations (you do not have to disclose the name of the } \\
\text { organization)? } \\
\text { Interview Questions: } \\
\text { The following questions I am going to ask you are more specific to the } \\
\text { central research question. You may give as much details as you can. } \\
\text { 1. What strategies did you use to integrate knowledge management } \\
\text { in your business practices? } \\
\text { 2. How did you disseminate these strategies within the organization? } \\
\text { 3. How did the integration of knowledge management in your } \\
\text { business practices affect the performance of your organization? } \\
\text { 4. How did the integration of knowledge management affect the } \\
\text { continuity in business of your organization? } \\
\text { 5. How are the knowledge management practices integrated into the } \\
\text { organization culture? } \\
\text { 6. What strategies do you have in place that help you to retain tacit } \\
\text { knowledge in your organization? } \\
\text { 7. What strategies do you have in place for sharing and retaining } \\
\text { 8. Whowledge? } \\
\text { 9. What additional comments, or experience regarding the use of } \\
\text { KM, do you have that you have not discussed? }\end{array}$ \\
\hline Wrap up interview thanking participant & $\begin{array}{l}\text { Thank you very much for your time and your contribution to this research } \\
\text { study. }\end{array}$ \\
\hline Schedule follow-up member checking interview & $\begin{array}{l}\text { I will go through the discussion we have had, synthesize it then I should be } \\
\text { able to come back to you with the synthesis for your validation. When can } \\
\text { we meet again for this? }\end{array}$ \\
\hline $\begin{array}{l}\text { I will introduce follow-up interview and set the } \\
\text { stage }\end{array}$ & $\begin{array}{l}\text { Thank you for turning up for this validation meeting. As promised, I have } \\
\text { done the synthesis for each of the interview questions we had last time. } \\
\text { Please go through to verify and see whether my interpretation is right and } \\
\text { make comments, correction or provide additional information. I will take } \\
\text { you through question by question. }\end{array}$ \\
\hline Share a copy of the succinct synthesis for each & Here is the printed copy. \\
\hline individual question & $\begin{array}{l}\text { 1. What strategies did you use to integrate knowledge management } \\
\text { in your business practices? }\end{array}$ \\
\hline
\end{tabular}


I will bring in probing questions related to other information that I may have found - note the information should be related so that as I probe I adhere to the IRB approval.

I will walk through each question, read the interpretation and ask:

Did I miss anything? Or, What would you like to add?
Succinct synthesis of the interpretation-perhaps one paragraph or as needed

2. How did you disseminate these strategies within the organization? Succinct synthesis of the interpretation - perhaps one paragraph or as needed

3. How did the integration of knowledge management in your business practices affect the performance of your organization? Succinct synthesis of the interpretation - perhaps one paragraph or as needed

4. How did the integration of knowledge management affect the continuity in business of your organization?

Succinct synthesis of the interpretation - perhaps one paragraph or as needed

5. How are the knowledge management practices integrated into the organization culture?

Succinct synthesis of the interpretation - perhaps one paragraph or as needed

6. What strategies do you have in place that help you to retain tacit knowledge in your organization?

Succinct synthesis of the interpretation - perhaps one paragraph or as needed

7. What strategies do you have in place for sharing and retaining knowledge?

Succinct synthesis of the interpretation - perhaps one paragraph or as needed

8. What computerized systems do you use to support the integration of knowledge management in your business practices?

Succinct synthesis of the interpretation-perhaps one paragraph or as needed

9. What additional comments, or experience regarding the use of $\mathrm{KM}$, do you have that you have not discussed?

Succinct synthesis of the interpretation - perhaps one paragraph or as needed
Appendix B: Proposed Framework for the Integration of Knowledge Management into Business Practice

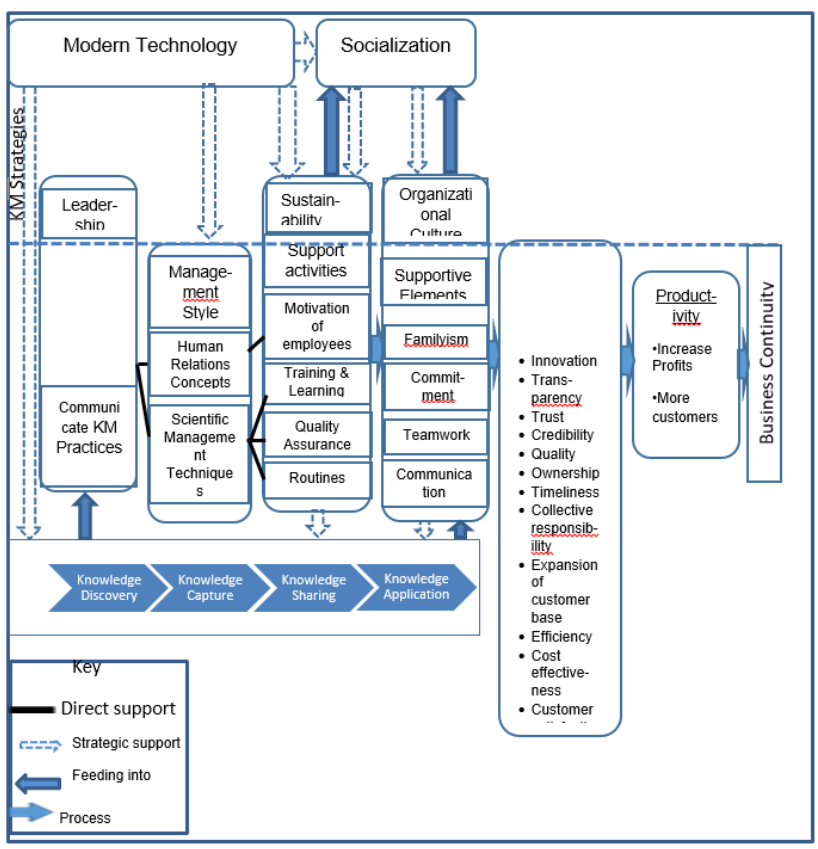

\section{REFERENCES}

[1] Ode, E., Ayavoo, R. (2020). The mediating role of knowledge application in the relationship between knowledge management practices and firm innovation. Journal of Innovation \& Knowledge, 5, 210-218.

[2] Mbhalati, O. J. (2014). Reinventing the public sector in Africa through knowledge management. Knowledge Management Research \& Practice, 121, 114-121.

[3] Lee, V. H., Foo, A. T. L., Leong, L. Y., \& Ooi, K. B. (2016). Can competitive advantage be achieved through knowledge management? A case study on SMEs. Expert Systems with Applications, 65, 136-151.

[4] Hsieh, C. T., Huang, H. C., \& Lee, W. L. (2016). Using transaction cost economics to explain open innovation in startups. Management Decision, 54, 2133-2156.

[5] Cerchione, R., \& Esposito, E. (2017). Using knowledge management systems: A taxonomy of SME strategies. International Journal of Information Management, 37, 15511562.

[6] Perez-Soltero, A., Zavala-Guerrero, A. G., Barcelo-Valenzuela, M., Sanchez-Schmitz, G., \& Meroño-Cerdan, A. L. (2015). A Methodology for the development and implementation of 
knowledge management strategy in a Mexican SME trading company. IUP Journal of Knowledge Management, 13, 25-44.

[7] Olupot, C., Kituyi, M. G., \& Noguera, J. (2014). Factors affecting the adoption of electronic customer relationship management information systems in SMEs. Journal of Studies in Social Sciences, 8, 37-47.

[8] Byukusenge, E., \& Munene, J. C. (2017). Knowledge management and business performance: Does innovation matter? Cogent Business \& Management, 4, 1-18.

[9] Durst, S., \& Edvardsson, I. R. (2012). Knowledge management in SMEs: A literature review. Journal of Knowledge Management, 16, 879-903.

[10] Ouchi, W. G., \& Price, R. L. (1978). Hierarchies, clans, and theory z: A new perspective on organization development. Organizational Dynamics, 7, 25-44.

[11] McGregor, D. M. (1960). The human side of enterprise. McGraw-Hill: New York.

[12] Indabawa, S. L., \& Uba, Z. (2014). Human relations and behavioral science approach to motivation in selected business organizations in Kano Metropolis Nigeria. European Journal of Business and Management, 6(25), 168-173.

[13] Pascale, R. T., \& Athos, A. G. (1981). The art of Japanese management. Business Horizons, 24(6), 83-85.

[14] Ouchi, W. G. (1980). Markets, bureaucracies, and clans. Administrative Science Quarterly, 25, 129-141.

[15] Houghton, C., Casey, D., Shaw, D., \& Murphy, K. (2013). Rigour in qualitative case-study research. Nurse Researcher, 20(4), 12-17.

[16] Skelton, O. G. (2015). Exploring knowledge management practices in service-based small business enterprises (Doctoral dissertation).

[17] Yin, R. K. (2018). Case study research: Design and methods (5th ed.). Sage.

[18] Morsink, S., Sonuga-Barke, E., Mies, G., Glorie, N., Lemiere, J., Van der Oord, S., \& Danckaerts, M. (2017). What motivates individuals with ADHD? A qualitative analysis from the adolescent's point of view. European Child \& Adolescent Psychiatry, 26, 923-932.

[19] Emerson, R. W. (2015). Convenience sampling, random sampling, and snowball sampling: How does sampling affect the validity of research? Journal of Visual Impairment \& Blindness, 109, 164-168.

[20] Onwuegbuzie, A. J., \& Leech, N. L. (2007). Sampling designs in qualitative research: Making the sampling process more public. The Qualitative Report, 12, 238-254.

[21] Kemparaj, U., \& Chavan, S. (2013). Qualitative research: A brief description. Indian Journal of Medical Sciences, 67, 89-98.

[22] Lemon, L. (2017). Applying a mindfulness practice to qualitative data collection. The Qualitative Report, 22, 33053313.

[23] Frels, R. K., \& Onwuegbuzie, A. J. (2013). Administering quantitative instruments with qualitative interviews: A mixed research approach. Journal of Counseling and Development, 91, 184-194.

[24] Neusar, A. (2014). To trust or not to trust? Interpretations in qualitative research. Human Affairs, 24(2), 178-188.

[25] Onwuegbuzie, A. J., \& Hwang, E. (2014). Interviewing successfully for academic positions: A framework for candidates for asking questions during the interview process. International Journal of Education, 6(2), 98-113.

[26] Robbins, G., Mulligan, E., \& Keenan, F. (2015). e-Government in the Irish revenue: The revenue on-line service (ROS): A success story? Financial Accountability \& Management, 31, 363-394.

[27] Wilson, V. (2014). Research methods: Triangulation. Evidence Based Library and Information Practice, 9(1), 74-75.

[28] Chou, C. H. (2017). Investigating EFL Elementary Student Teachers' Development in a Professional Learning Practicum. In J. Mena, A. García-Valcárcel, F. J. García Peñalvo, M. Martín del Pozo Search and research: Teacher education for contemporary contexts (pp. 309-318).

[29] Dattalo, M., Wise, M., Ford Ii, J. H., Abramson, B., \& Mahoney, J. (2017). Essential resources for implementation and sustainability of evidence-based health promotion programs: A mixed methods multi-site case study. Journal of Community Health, 42, 358-368.

[30] Jessor, R., Graves T. D., Hanson R. C., Jessor S. L. (2016). Problem behavior theory: Initial formulation for the Tri-Ethnic Community study. In Jessor, R., The Origins and Development of Problem Behavior Theory (pp. 43-55).

[31] Sahu, M., Sharma, S., Raj, V., Nagwani, N. K., \& Verma, S. (2016). Impact of ranked ordered feature list (ROFL) on classification with visual data mining techniques. In 2016 International Conference on Electrical, Electronics, and Optimization Techniques (ICEEOT), (pp. 3183-3188). IEEE.

[32] Taylor, P., Dowding, D., \& Johnson, M. (2017). Clinical decision making in the recognition of dying: A qualitative interview study. BMC Palliative Care, 16(1), 1-11.

[33] You, X., Li, Y., \& Zhu, Z. (2017). DRSO-EGSM: Data replication strategy oriented to automatic energy gear-shifting mechanism. International Journal of Wireless and Mobile Computing, 13, 291-298.

[34] Burr, V., King, N., \& Butt, T. (2014). Personal construct psychology methods for qualitative research. International Journal of Social Research Methodology, 17, 341-355.

[35] Schlomer, B. J., \& Copp, H. L. (2014). Secondary data analysis of large data sets in urology: Successes and errors to avoid. The Journal of Urology, 191, 587-596.

[36] Bianchi, V., Ceol, A., Ogier, A. G., de Pretis, S., Galeota, E., et al. (2016). Integrated systems for NGS data management and analysis: Open issues and available solutions. Frontiers in Genetics, 7, 1-8.

[37] Joslin, R., \& Müller, R. (2016). Identifying interesting project phenomena using philosophical and methodological triangulation. International Journal of Project Management, 34, 1043-1056.

[38] Fusch, P., Fusch, G. E., \& Ness, L. R. (2018). Denzin's paradigm shift: Revisiting triangulation in qualitative research. Journal of Social Change, 10, 19-32.

[39] Castleberry, A., \& Nolen, A. (2018). Thematic analysis of qualitative research data: Is it as easy as it sounds? Currents in Pharmacy Teaching and Learning, 10, 807-815.

[40] Tuapawa, K. (2017). Interpreting experiences of students using educational online technologies to interact with teachers in blended tertiary environments: A phenomenological study. Australasian Journal of Educational Technology, 33, 163-175. 
[41] Hogan, S. P., Perks, K. J. \& Russell-Bennett, R. (2014). Identifying the key sociocultural influences on drinking behavior in high and moderate binge-drinking countries and the public policy implications. Journal of Public Policy \& Marketing, 33, 93-107.

[42] Saltan, F. (2017). Blended learning experience of students participating pedagogical formation program: Advantages and limitation of blended education. International Journal of Higher Education, 6(1), 63-73.

[43] Williams, P. A., Furberg, R. D., Bagwell, J. E., \& LaBresh, K. A. (2016). Usability testing and adaptation of the pediatric cardiovascular risk reduction clinical decision support tool. JMIR Human Factors, 3, e17.

[44] Essary, M. L. (2014). Key external factors influencing successful distance education programs. Academy of Educational Leadership Journal, 18, 121-136.

[45] Dillaway, H., Lysack, C., \& Luborsky, M. R. (2017). Qualitative approaches to interpreting and reporting data. In R. R. Taylor, Kielhofner's Research in Occupational Therapy: Methods of Inquiry for Enhancing Practice (2nd ed.) (pp. 228-243).

[46] Nissanov, Z. (2017). Concluding comments. In Economic Growth and the Middle Class in an Economy in Transition (pp. 103-106).

[47] Crilly, P., Patel, N., Ogunrinde, A., Berko, D., \& Kayyali, R. (2017). Community Pharmacists' involvement in research in the United Kingdom. Pharmacy, 5, 48-57.

[48] Forman, E. A., Ramirez-DelToro, V., Brown, L., \& Passmore, C. (2017). Discursive strategies that foster an epistemic community for argument in a biology classroom. Learning and Instruction, 48, 32-39.

[49] Hussein, A. (2009). The use of triangulation in social sciences research: Can qualitative and quantitative methods be combined? Journal of Comparative Social Work, 4(1), 1-12.

[50] Johnson, M., O’Hara, R., Hirst, E., Weyman, A., Turner, J., Mason, Quinn, T., Shewan, J., \& Siriwardena, A. N. (2017). Multiple triangulation and collaborative research using qualitative methods to explore decision making in pre-hospital emergency care. BMC Medical Research Methodology, 17(1), $1-11$.

[51] Anney, V. N. (2014). Ensuring the quality of the findings of qualitative research: Looking at trustworthiness criteria. Journal of Emerging Trends in Educational Research and Policy Studies (JETERAPS) 5, 272-281.

[52] U.S. National Commission for the Protection of Human Subjects of Biomedical and Behavioral Research. (1979). The Belmont Report: Ethical principles and guidelines for the protection of human subjects of research (SuDoc No. Y3.H88:2B41). Government Printing Office.

[53] Anbary, A., \& Nguyen, L. (2017). Knowledge retention in Vietnam-based management consulting SMEs (Master's thesis).

[54] Aithal, P. S., \& Kumar, P. M. (2016). Organizational behaviour in 21 st century - 'Theory $\mathrm{A}^{\prime}$ for managing people for performance. IOSR Journal of Business and Management (IOSR-JBM), 18, 126-134.

[55] Ismail, M., B., M. (2014). Categorization of organization: An application of type $\mathrm{A}$, type $\mathrm{J}$ and type $\mathrm{Z}$ dimensions. In the Proceedings of the Second ARC, FMC, SEUSL (pp. 239-247).

[56] Ogbu, O. J., \& Oaya, Z. C. T. (2017). Impact of culture on employee performance: A study of a savings and loans firm.
International Journal of Management Science Research, 3, 6582.

[57] Ouchi, W. (1981). Theory Z: How American business can meet the Japanese challenge. Business Horizons, 24(6), 82-83.

[58] Ho, S., Mohd Hashim, A. G. B., \& Mohd Idris, M. A. (2015). Applicability of SIRIM Green 5-S Model for productivity \& business growth in Malaysia. The TQM Journal, 27, 185-196.

[59] El Khouly, S., \& Fadl, N. (2016). The impact of organizational culture on work quality. Competition Forum 14, 210-215.

[60] Benton, C. F., \& Magnier-Watanabe, R. (2014). The impact of commitment, empowerment, embeddedness on knowledge management in domestic and foreign affiliated firms in Japan. Knowledge Management Research \& Practice, 12, 161-174.

[61] Jankurová, A., Ljudvigová, I., \& Gubová, K. (2017). Research of the nature of leadership activities. Economics \& Sociology, $10,135-151$

[62] Fang, L. F., Li, X. D., \& Li, A. B. (2015). Analysis of the symbiotic relationship between managers and staff with an application for coal mine safety management. International Journal of Engineering Research in Africa, 16, 156-165.

[63] Elegbe, O., \& Ibikunle, F. F. (2015). Effective communication and participative decision-making in selected organizations in Ibadan metropolis. African Journal of Stability and Development, 9, 38-55.

[64] Scuotto, V., Del Giudice, M., \& Omeihe, K. O. (2017). SMEs and mass collaborative knowledge management: toward understanding the role of social media networks. Information Systems Management, 34, 280-290.

[65] Shvetsova, O. A., Shokola, Y. V., \& Bobova, A. S. (2017). Behavioural models of Russian and Finnish high tech companies. In Young Researchers in Electrical and Electronic Engineering (EIConRus), 2017 IEEE Conference of Russian (pp. 1355-1359). IEEE.

[66] Abu Baker, A. H., \& Yosof, M. N. (2016). Relating knowledge management and growth performance with organization learning as mediator: A conceptual approach. Journal of Fisheries and Hydrobiology, 11, 51-57.

[67] Schniederiansa, D. G., Curadob, C., Khalaihedavatia, M. (2020). Supply digitistion trends: An integration of knowledge management. International Journal of Production Economics, 220, Article 107439

[68] Cerchione, R., Esposito, E., \& Spadaro, M. R. (2015). The spread of knowledge management in SMEs: A scenario in evolution. Sustainability, 7, 10210-10232.

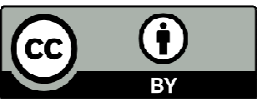

(C) 2021 by the Dr. Josephine K. NsubugaMugoa, Dr. Irene A. Williams and Dr. Jorge Gaytan. Submitted for possible open access publication under the terms and conditions of the Creative Commons $\left.\begin{array}{llll}\text { Attribution } & (\mathrm{CC} & \mathrm{BY}\end{array}\right)$ (http://creativecommons.org/licenses/by/4.0/). 